The FASEB Journal express article 10.1096/fj.02-0034fje. Published online August 7, 2002.

\title{
The role of caspases in cryoinjury: caspase inhibition strongly improves the recovery of cryopreserved hematopoietic and other cells
}

\author{
Christopher Stroh, ${ }^{*} \dagger$ Uwe Cassens, ${ }^{\star}$ Ajoy K. Samraj, ${ }^{* \dagger}$ Walter Sibrowski, ${ }^{\ddagger}$ \\ Klaus Schulze-Osthoff, ${ }^{*} \dagger$ and Marek Los ${ }^{*}$ \\ *Institute of Experimental Dermatology, University of Münster, D-48149 Münster; ${ }^{\dagger}$ Institute of \\ Molecular Medicine, University of Düsseldorf, D-40225 Düsseldorf; ${ }^{\star}$ Institute of Transfusion \\ Medicine, University of Münster, D-48149 Münster, Germany \\ Corresponding author: Marek Los, Institute of Experimental Dermatology, University of \\ Münster, Röntgenstrasse 21, D-48149 Münster, Germany. E-mail: los@uni-muenster.de \\ Klaus Schulze-Osthoff and Marek Los share senior authorship.
}

\section{ABSTRACT}

Cryopreserved cells and tissues are increasingly used for stem cell transplantation and tissue engineering. However, their freezing, storage, and thawing is associated with severe damage, suggesting the need for better cryopreservation methods. Here, we show that activation of caspase- 3 is induced during the freeze-thaw process. Moreover, we demonstrate that prevention of caspase activation by the caspase inhibitor zVAD-fmk strongly improves the recovery and survival of several cryopreserved cell types and hematopoietic progenitor cells. A short preincubation with the caspase inhibitor after thawing also enhances the colony-forming activity of hematopoietic progenitor cells up to threefold. Furthermore, overexpression of Bcl-2, but not the blockade of the death receptor signaling, confers protection, indicating that cryoinjuryassociated cell death is mediated by a Bcl-2-controlled mitochondrial pathway. Thus, our data suggest the use of zVAD-fmk as an efficient cryoprotective agent. The addition of caspase inhibitors may be an important tool for the cryopreservation of living cells and advantageous in cell transplantation, tissue engineering, and other genetic technologies.

Keywords: apoptosis $\bullet$ cryopreservation $\bullet$ stem cells $\bullet$ cathepsins $\bullet$ calpains

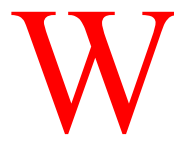

ith the recent advances in cell and tissue transplantation, tissue engineering, in vitro fertilization, and other genetic technologies, preservation of biological materials has become increasingly important in medical care and biotechnological industries. Cryopreservation is the only reliable form of long-term storage of viable cells and tissues. However, both the freeze and the thaw process result in considerable cell and tissue injury $(1,2)$. Various mechanisms, including oxidative stress, mechanical injury due to ice crystal formation, altered physical properties of cellular structures, osmotic injury, and disturbed ion homeostasis due to $\mathrm{Na}^{+} / \mathrm{K}^{+}$-ATPase inhibition are responsible for cell damage during hypothermia and freezethaw processes (3-8). Traditional protocols rely on supplementation of the freeze medium with 
penetrating cryoprotectants such as dimethyl sulfoxide (DMSO), glycerol, ethylene glycol, or hydroxyethyl starch (2). Their major role is the prevention of lethal ice formation and osmotic injury. Stabilization of cellular structures with small carbohydrate sugars such as trehalose has recently been shown to also markedly improve cell recovery (9).

Despite significant improvements of cryopreservation protocols, clinical procedures are often not satisfactory, and up to $50 \%$ of the cryopreserved cells may die within the first $24 \mathrm{~h}$ after the thaw process $(10)$. There are some indications that hypothermia is associated with apoptosis $(9,11)$, although the role of apoptosis in cryoinjury has not been studied in detail. Because inhibition of proteases of the caspase family protects against apoptosis in various experimental settings (1215), we examined whether addition of the caspase inhibitor zVAD-fmk has a beneficial effect on cell survival during the freeze-thaw process. Here, we show that the proapoptotic activity of caspase-3 is markedly induced during the freeze-thaw process. Furthermore, we demonstrate that addition of zVAD-fmk, but not of calpain or cathepsin inhibitors, greatly improves the survival and recovery of cryopreserved cell lines, primary cells, and hematopoietic progenitor cells (HPC). When the caspase inhibitor was added to methylcellulose cultures of cryopreserved HPC, the colony formation by progenitor cells increased two- to threefold. Cryoinjury-associated cell death is mediated by the mitochondrial apoptosis pathway, because Bcl-2 overexpression, but not the blockade of death receptors, considerably improved cell survival. Thus, our results suggest that $\mathrm{zVAD}$-fmk is a potent cryoprotectant. The presence of caspase inhibitors may therefore improve the preservation of biological materials used in cell engraftment, hematopoietic reconstitution, and organ transplantation.

\section{MATERIALS AND METHODS}

\section{Cell culture and reagents}

All cells were maintained at $37^{\circ} \mathrm{C}$ and $5 \% \mathrm{CO}_{2}$ in RPMI 1640 medium supplemented with $10 \%$ fetal calf serum (FCS), $100 \mathrm{U} / \mathrm{ml}$ penicillin, $100 \mu \mathrm{g} / \mathrm{ml}$ streptomycin, and $2 \mathrm{mM}$ L-glutamine (all from Gibco Life Technologies, Karlsruhe, Germany). FADD-deficient Jurkat cells (16) and the parental Jurkat cell line A3 were kindly provided by J. Blenis (Boston, MA). Stable transfectants of Jurkat cells overexpressing c-FLIP, Bcl-2, or Bcl- $\mathrm{x}_{\mathrm{L}}$ have been described previously (17-20) and were a kind gift of J. Tschopp (Lausanne, Switzerland), H. Walczak (Heidelberg, Germany), and C. Belka (Tübingen, Germany), respectively. Splenocytes were isolated from pathogen-free $\mathrm{BALB} / \mathrm{c}$ mice. Single cell suspensions were obtained after filtration through a nylon gauze (Cell Strainer, Falcon-Becton Dickinson, Heidelberg, Germany) and removal of erythrocytes was done by Ficoll-Hypaque gradient centrifugation.

The caspase inhibitor zVAD-fmk (benzyloxycarbonyl-Val-Ala-Asp-fluoro-methylketone) was purchased from Enzyme Systems (Dublin, CA). N-Acetyl-Leu-Leu-norleucinal, (ALLN), an inhibitor of calpain, and N-acetyl-Leu-Leu-methional (ALLM), which inhibits calpain as well as cathepsins, were from Biomol (Hamburg, Germany). The cathepsin B-specific inhibitor CA-074ME was obtained from Peptide Institute, Inc. (Osaka, Japan), and staurosporine was obtained from Roche Molecular Biochemicals (Mannheim, Germany). The agonistic anti-CD95 antibody was obtained from BioCheck (Münster, Germany). All other chemicals were either from Sigma (Deisenhofen, Germany) or Carl Roth GmbH (Karlsruhe, Germany). 


\section{Hematopoietic progenitor cells and clonogenicity assays}

HPC derived from peripheral blood were isolated by large volume leukapheresis from patients with hematological malignancies and solid tumors as previously described (21). Clonogenicity was determined by measuring colony formation in methylcellulose cultures (22). In brief, after they were thawed and washed, stem cells were adjusted to a final concentration of $5 \times 10^{4}$ per ml in $5 \mathrm{ml}$ culture medium. Then, $30 \mu \mathrm{M}$ of the caspase inhibitor zVAD-fmk or the solvent control were added for $2 \mathrm{~h}$ at $4^{\circ} \mathrm{C}$. After the cells were washed with RPMI 1640/10\% FCS, $5 \times 10^{4}$ cells were seeded in duplicates onto $1 \mathrm{ml}$ methylcellulose medium (Methocult H-4434; Stem Cell Technologies, Vancouver, Canada) in $35-\mathrm{mm}^{2}$ plates. For long-term caspase inhibition, the methylcellulose medium was directly supplemented with $30 \mu \mathrm{M}$ zVAD-fmk. Two weeks later, the number of erythroid progenitor cell-derived colonies (BFU-E) and granulocyte-macrophage progenitor-derived colonies (CFU-GM) was determined.

\section{Cryopreservation techniques}

HPC were frozen within $24 \mathrm{~h}$ after harvest in 10\% DMSO (21). Cryopreservation was achieved with a rate-controlled freezing system (Planer Kryo-10 II, TS Scientific) using a cooling rate of $1{ }^{\circ} \mathrm{C} / \mathrm{min}$. Splenocytes and cell lines were frozen in 40\% FCS and 10\% DMSO and stored in liquid nitrogen or in a freezer at $-70^{\circ} \mathrm{C}$. Frozen cells were thawed rapidly in a $37^{\circ} \mathrm{C}$ water bath with continuous agitation and were diluted 1:10 with culture medium. Addition and removal of zVAD-fmk during the freeze and postfreeze processes was performed as indicated.

\section{Measurement of cell death and cell growth}

Cell death was measured either by the detection of hypodiploid nuclei (Nicoletti method) (23) or by the uptake of propidium iodide (PI), and trypan blue, respectively $(24,25)$. For measurement of hypodiploid DNA, nuclei were prepared by lysing $5 \times 10^{4}$ cells in $100 \mu 1$ of hypotonic lysis buffer ( $1 \%$ sodium citrate, $0.1 \%$ Triton X-100, and $50 \mu \mathrm{g} / \mathrm{ml} \mathrm{PI)}$ and were subsequently analyzed by flow cytometry, using a FACScalibur (Becton Dickinson, Heidelberg, Germany) and CellQuest analysis software. To assess PI uptake, cells were harvested after the indicated times and incubated with PI $(2 \mu \mathrm{g} / \mathrm{ml})$. The uptake of PI into nonfixed cells was measured by flow cytometry, using the FSC/FL2 profile. To measure trypan blue exclusion, cells were incubated in triplicates in a $0.25 \%$ dye solution. The number of total and trypan blue-positive cells was then determined by counting at least 300 cells per sample in a Neubauer chamber. To measure cell confluency, we plated cells in six-well plates in the presence and absence of the indicated concentrations of zVAD-fmk. After $24 \mathrm{~h}$, the inhibitor was replaced by normal growth medium. Cell confluency was examined after 4 days of culture independently by two individuals using a microscope equipped with a 100-field raster ocular. At least three areas (300 fields) were examined for each sample.

\section{Myc-induced apoptosis}

Rat-1 and Rat-1-Myc-ER cells carrying an estrogen-inducible c-Myc protooncogene (26) were stably transfected by electroporation with linearized pSV25S-CrmA (13), pPGK-Hygro carrying 
a hygromycin resistance gene, or the appropriate vector controls. Positive clones were selected with $600 \mu \mathrm{g} / \mathrm{ml}$ hygromycin, and expression of CrmA was confirmed by immunoblot analysis. To induce apoptosis, cells were grown in $0.3 \% \mathrm{FCS}$, and $2 \mathrm{~h}$ later, they were stimulated with 1 $\mu \mathrm{M}$ 17- $\beta$-estradiol (Sigma, Deisenhofen, Germany).

\section{Immunoblot analysis and DEVDase assay}

The processing and activation of caspase- 3 were measured by immunoblotting as well as by fluorogenic substrate assays as described previously $(23,27) .1 \times 10^{6}$ phosphate-buffereed saline (PBS)-washed cells were lysed in a high-salt buffer containing 1\% NP-40, 20 mM HEPES (pH 7.9), $350 \mathrm{mM} \mathrm{NaCl}, 20 \%$ glycerol, $1 \mathrm{mM} \mathrm{MgCl}$, $0.5 \mathrm{mM}$ EDTA, $0.1 \mathrm{mM}$ EGTA, $0.5 \mathrm{mM}$ DTT, $3 \mu \mathrm{g} / \mathrm{ml}$ aprotinin, $3 \mu \mathrm{g} / \mathrm{ml}$ leupeptin, $3 \mu \mathrm{g} / \mathrm{ml}$ pepstatin $\mathrm{A}$, and $2 \mathrm{mM}$ phenylmethylsulfonyl fluoride. Subsequently, we separated proteins under reducing conditions on a $15 \%$ sodium dodecyl sulfate (SDS)-polyacrylamide gel and electroblotted to a polyvinylidene difluoride membrane (Amersham, Braunschweig, Germany). Membranes were blocked for $1 \mathrm{~h}$ with 5\% nonfat dry milk powder in TRIS-buffered saline and then immunoblotted for $1 \mathrm{~h}$ with polyclonal goat antibodies against caspase-3 (R\&D Systems, Minneapolis, MN). Caspase-3-like activity was also determined by incubation of cell lysates with $50 \mu \mathrm{M}$ of the fluorogenic substrate DEVD-AMC (N-acetyl-Asp-Glu-Val-Asp-aminomethylcoumarin, Bachem, Heidelberg, Germany) in $200 \mu \mathrm{l}$ buffer containing $50 \mathrm{mM}$ Hepes (pH 7.3), $100 \mathrm{mM} \mathrm{NaCl}, 10 \%$ sucrose, 0.1\% CHAPS (3-[(3-cholamidopropyl)dimethylammonio]-1-propane-sulfonate), and $10 \mathrm{mM}$ DTT (1,4-dithiothreitol). The release of aminomethylcoumarin was measured by fluorometry, using an excitation wavelength of $360 \mathrm{~nm}$ and an emission wavelength of $475 \mathrm{~nm}$.

\section{RESULTS}

\section{Caspase inhibition improves recovery from cryopreservation}

We first investigated the effect of caspase inhibition during thawing of several cryopreserved cell lines that were frozen in liquid nitrogen for more than 5 years. Equal numbers of Jurkat T-cells, HeLa cervix cells, and 293 kidney carcinoma cells were transferred from liquid nitrogen into standard growth medium or into medium supplemented with various concentrations of the irreversible caspase inhibitor zVAD-fmk. Twenty-four hours later, the medium was replaced in order to remove the inhibitor. After 4 days, all cell lines that had obtained zVAD-fmk grew to a markedly higher density than the controls without zVAD-fmk, indicating strongly improved cell survival upon caspase inhibition (ig. 1A). The enhanced survival conferred by $\mathrm{zVAD}$-fmk showed a clear dose dependency. Maximal effects were obtained in the range of $20-40 \mu \mathrm{M}$, whereas higher concentrations of zVAD-fmk were less effective.

Additional evidence for a cryoprotective effect of caspase inhibition was provided by Rat-1MycER cells that were transfected with the caspase inhibitor CrmA (Fig. 1B). Rat-1-MycERCrmA cells showed in the average a threefold higher confluency 4 days after thawing than did Rat-1-MycER cells not expressing CrmA. This underlines the positive effect of caspase inhibition on the survival of cryopreserved cells. Note that further supplementation of the growth medium with zVAD-fmk led to an improvement in the recovery of both cell lines but was less effective in the CrmA-expressing cells. 
Cells incubated with zVAD-fmk had a normal microscopic appearance. Nevertheless, it could not be ruled out that caspase inhibition had an influence on cell physiology. To assess this point, we used Rat-1-MycER cells in which activation of the c-Myc oncogene is triggered by incubation with $\beta$-estradiol (26). In the presence of the hormone, Rat-1-MycER cells underwent apoptosis following serum deprivation. Rat-1-MycER cells treated with zVAD-fmk during the first $24 \mathrm{~h}$ after thawing were equally sensitive to serum withdrawal after c-Myc induction as their untreated counterparts (Fig.1C). c-Myc-induced apoptosis is cell cycle-dependent and requires de novo protein synthesis as well as the activation of several signaling pathways $(28,29)$, this indicates that zVAD-fmk does not have broad unspecific effects.

\section{Activation of caspase- 3 and effects of $\mathrm{zVAD}-\mathrm{fmk}$ in the freeze and postfreeze process}

We also explored whether not only caspase inhibition after thawing, but already the presence of zVAD-fmk during freezing and storage had a protective effect on cryopreserved cells cells. The monocytic cell line MonoMac-6 and murine splenocytes were frozen in medium with or without zVAD-fmk and stored for 14 months either in liquid nitrogen or at $-70^{\circ} \mathrm{C}$. When transferred into culture, the cells that were frozen and stored in the presence of $\mathrm{zVAD}$-fmk again displayed a significantly higher viability than the controls, as assessed by trypan blue exclusion $2 \mathrm{~h}$ after thawing (Fig. 2A $)$. In most cells tested, the protection conferred by the caspase inhibitor was stronger in cells kept at $-70^{\circ} \mathrm{C}$, a condition that fosters cryoinjury more than preservation in liquid nitrogen (30). A further decrease in the number of dead cells was noticed when zVADfmk also was added to the growth medium during thawing. Remarkably, the combined use of zVAD-fmk both in the freeze and the growth medium of cells stored at $-70^{\circ} \mathrm{C}$ suppressed cell death to an extent that was otherwise obtained under optimal conditions in liquid nitrogen without supplementation of zVAD-fmk (Fig. 2B).

To confirm that the observed effects were indeed due to inhibition of caspase activation, Jurkat cells were frozen in liquid nitrogen in the absence or presence of different $\mathrm{zVAD}$-fmk concentrations. After $3 \mathrm{wk}$, cells were thawed and transferred into growth medium with or without zVAD-fmk. Six hours later the cells were lysed, and caspase-3-like DEVDase activity and caspase-3 processing were determined by fluorogenic substrate assays and immunoblot analyses, respectively (Fig. 2C). In cells that were frozen and thawed in the absence of zVADfmk, a strong DEVDase activity was measured in accordance with the appearance of the p17 and p12 subunits of active caspase-3. This indicated that the freeze-thaw process indeed induced proapoptotic caspase activation. Addition of zVAD-fmk solely to the freeze medium led to a marked decrease of DEVDase activity and caspase-3 activation. An even stronger inhibition was observed when zVAD-fmk was added to the growth medium during the thaw cycle. In this case, DEVDase activity and caspase-3 processing were almost completely suppressed. The same results were obtained with MCF-7 cells stably expressing caspase-3 and 293 cells (data not shown).

Cryoinjury-induced apoptosis is mediated by a death receptor-independent Bcl-2controlled caspase pathway that does not involve calpain or cathepsins 
Apoptosis can be mediated via two principal signaling pathways: the extrinsic and intrinsic death pathways. The extrinsic death pathway involves the ligation of death receptors that leads to the recruitment of the adapter molecule FADD and caspase- 8 into a death-inducing signaling complex $(31,32)$. The intrinsic death pathway is initiated at the mitochondrion by the release of cytochrome $c$, a process that can be inhibited by anti-apoptotic proteins of the Bcl-2 family. To obtain insights into the pathway of cryoinjury-induced apoptosis, we used Jurkat cell clones that were either deficient for FADD or overexpressed Bcl-2. As measured by the formation of hypodiploid nuclei (Fig. 3A, left panel), the lack of FADD only weakly attenuated cryoinjury,

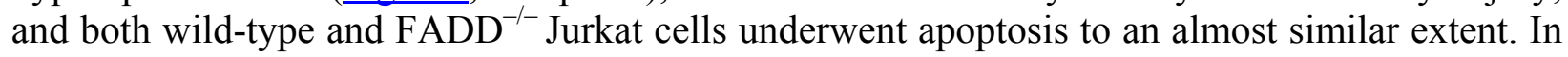
contrast, apoptosis induced by agonistic anti-CD95 that was used as a positive control was strongly abrogated in the FADD-deficient cells. Furthermore, overexpression of c-FLIP, an inhibitor of caspase-8, as well as neutralizing anti-CD95 ligand antibodies did not confer protection against cryoinjury-induced apoptosis (data not shown).

Having shown that death receptor signaling is not required for cryoinjury-induced cytotoxicity, we examined the possibility that caspase activation is mediated via the intrinsic mitochondrial pathway. Cell death induced by the freeze-thaw process was strongly inhibited in Jurkat cells overexpressing the anti-apoptotic proteins Bcl-2 (Fig. 3A , right panel) or Bcl- $\mathrm{x}_{\mathrm{L}}$ (data not shown) compared with Jurkat cells transfected with the empty vector alone. Similarly, overexpression of Bcl-2 strongly protected against staurosporine, a known inducer of the mitochondrial pathway. Both in $\mathrm{FADD}^{-/}$and vector control cells, apoptosis induced by the freeze-thaw process was very efficiently abrogated by zVAD-fmk, whereas in the apoptosis-resistant Jurkat Bcl-2 cells, the caspase inhibitor did not strongly confer additional protection.

Accumulating evidence suggests that noncaspase proteases such as calpain and cathepsins can act either in concert with or independently of caspases in various death processes (33). Therefore, Jurkat cells were incubated with various protease inhibitors such as ALLN, a calpain inhibitor, and ALLM, an inhibitor that in addition to calpain also potently inhibits cathepsin L $(\mathrm{Ki}=0.6 \mathrm{nM})$ and $\mathrm{B}(\mathrm{Ki}=0.1 \mu \mathrm{M})$. However, none of these compounds could prevent cryoinjury-induced cell death in Jurkat cells (Fig. 3B) or MonoMac-6 cells (data not shown), even when applied at maximal tolerated concentrations. In addition, CA-074-ME, a cathepsin Bspecific inhibitor, also had no effect (data not shown), suggesting that none of these proteases is involved in the cell death pathway triggered upon cryoinjury. Together, these results demonstrate that cryoinjury triggers a mitochondrial apoptotic pathway that is caspase-dependent but does not require death receptors or other cysteine proteases.

\section{Caspase inhibition greatly improves the colony-forming activity of hematopoietic progenitor cells}

Cryopreservation is widely used for the storage and subsequent transplantation of hematopoietic progenitor cells (HPC) in the treatment of cancer, inborn errors of metabolism, and immunodeficiencies. The clinical use of HPC requires efficient cryopreservation and recovery protocols $(34,35)$. To assess the effect of caspase inhibition on the recovery of HPC, we used colony assays with peripheral blood-derived progenitor cells. In this method, normally used to appraise the quality of stem cells, cryopreserved HPC from different patients were thawed and cultured on methylcellulose. Two weeks later, the number of burst-forming units representing 
erythroid colonies (BFU-E) and colony-forming units representing granulocyte-macrophage progenitors (CFU-GM) were counted. Figure 4A shows representative data with HPC derived from one patient. Preincubation of HPC with $30 \mu \mathrm{M}$ of zVAD-fmk for $2 \mathrm{~h}$ at $4{ }^{\circ} \mathrm{C}$ before plating caused a two- to threefold increase in colony numbers. In addition, already 10 min preincubation with zVAD-fmk exhibited a significant protective effect (data not shown). However, addition of the caspase inhibitor to the methylcellulose medium and continued culture in the presence of zVAD-fmk slightly inhibited colony formation, indicating that, in contrast to short-term inhibition, prolonged inhibition of caspases might impair cell survival. We also examined whether caspase inhibition changed the colony composition and cellular differentiation of HPC by comparing the BFU-E/CFU-GM ratio. We did not detect significant differences in the overall colony composition after short preincubation or after long-term culture with zVAD-fmk (Fig. $\underline{4 B})$.

\section{DISCUSSION}

These results clearly demonstrate that the use of a caspase inhibitor as a cryoprotective agent allows for successful cryopreservation and recovery of cells. We show for the first time that the freeze-thaw process is associated with caspase activation, suggesting that apoptosis plays an important role in the cryoinjury of cells. Consequently, we demonstrate that the inhibition of caspases, either by overexpression of CrmA and Bcl-2 or by addition of the pharmacological inhibitor zVAD-fmk, prevents caspase activation and greatly enhances the recovery and survival of cryopreserved cells. The protective effect of zVAD-fmk was observed in various cell lines such as Jurkat, 293, HeLa, MCF-7, MonoMac-6, and Rat-1 cells as well as in primary cells such as splenocytes and HPC. The caspase inhibitor was protective when added to both the freeze solution and the culture medium during the thaw process. Furthermore, addition of zVAD-fmk in the freeze and postfreeze process prevented the activation of caspase-3. When cells were frozen in the absence of zVAD-fmk but thawed in the presence of the caspase inhibitor, already a significant inhibition of cryoinjury and caspase activation was observed. This suggests that in particular the thaw process is associated with apoptosis induction. Note that the application of zVAD-fmk proved to be beneficial not only for the survival of cells kept in liquid nitrogen but especially for cells that were stored under suboptimal conditions at $-70^{\circ} \mathrm{C}$. This observation might be of relevance for conditions when storage or transportation facilities in liquid nitrogen are not available.

To analyze the signaling pathway involved in cryoinjury-induced apoptosis, we investigated cell clones that either overexpressed anti-apoptotic Bcl-2 proteins or were deficient for the death receptor-associated protein FADD. Cells overexpressing Bcl-2 or Bcl- $\mathrm{x}_{\mathrm{L}}$ were strongly protected against cryoinjury. In contrast, the blockade of death receptor signaling, either by the deficiency of FADD, the overexpression of c-FLIP, or neutralizing CD95 ligand antibodies, had almost no effects on cryoinjury-induced cell death. In addition, protease inhibitors against calpain and cathepsins did not prevent cryoinjury, arguing against an involvement of any of these proteases in our system. Our data therefore indicate that the mitochondrial apoptosome pathway is the principal mediator of cryoinjury-induced apoptosis. This is in line with the observation that induction of cryoinjury-mediated apoptosis is a rapid process, with morphological changes visible within hours after thawing. Under such conditions, cells presumably lack the time required to express de novo death ligands and to trigger death receptors in an autocrine manner. 
An important finding was the observation that addition of the caspase inhibitor significantly improved the recovery of HPC. We were able to increase the colony-forming activity of cryopreserved HPC up to threefold by a short treatment with zVAD-fmk after thawing. HPC are currently of high interest for their use in bone marrow transplantation and other applications. A successful transplantation largely depends on preserving the viability of the cells during cryopreservation. The engraftment failure for allogenic transplantations varies between 10 and $20 \%$ (36). Therefore, our finding may provide a way to improve the rate of successful cell engraftments.

An important question to address was whether zVAD-fmk could cause side effects. In the Rat-1MycER model, we were unable to detect changes in the sensitivity of cells to undergo apoptosis, which is a complex, cell cycle-dependent process in the c-Myc-induced pathway $(28,29)$. Moreover, we found no significant differences in the colony composition of HPC after zVADfmk treatment. However, our data also suggest that short-term inhibition of caspases is superior to the use of zVAD-fmk for prolonged cell culture. The finding that long-term exposure to zVAD-fmk in colony assays and higher inhibitor concentrations were less protective might be explained by a potential toxicity of the caspase inhibitor. In Jurkat cells, the caspase inhibitor was considerably less toxic than calpain and cathepsin inhibitors. It was previously shown that Jurkat cells rescued from CD95-induced apoptosis by zVAD-fmk even at concentrations of 200 $\mu \mathrm{M}$ retained their proliferative and colony-forming capacity (37). The inhibitory effect of longterm exposure to caspase inhibitors might also indicate that caspases play a role in processes unrelated to programmed cell death. It has been proposed that caspase activity may be involved in processes such as cell-cycle progression and cell differentiation $(38,39)$. For instance, caspase activation can positively and negatively affect erythropoiesis. Caspase-mediated cleavage of the transcription factor GATA-1 has been shown to impede early stages of erythropoiesis (40), whereas caspase activation might be required for later stages during the enucleation of erythroblasts (41). Caspases may also affect hematopoiesis by their effect on the maturation of inactive cytokine precursors such as IL-1 $\beta$, IL-16, IL-18, and others (14).

Previously, a potential role of apoptosis in cryoinjury had been discussed, but the molecular mechanisms remained unknown (42). Here, we show for the first time that caspases, in particular caspase-3, are indeed activated upon cryoinjury. Our data suggest the short-term use of zVADfmk or other pharmacological caspase inhibitors as cryoprotective agents. Caspase inhibitors might not only be beneficial for stem cell transplantation but also for other applications that require preservation of biological materials. It is conceivable that apoptosis might be involved in the damage of organs and tissues that are stored by cooling or freezing during transport before transplantation. Finally, the increasing use of cryopreserved germ cells and embryonic stem cells requires better cryopreservation methods. Because apoptosis is involved in cryoinjury, caspase inhibitors in combination with other cryoprotectant agents might be important for the long-term storage of living cells and critical for the success of tissue engineering, cell and tissue transplantation, and other modern genetic technologies. 


\section{ACKNOWLEDGMENTS}

We thank Drs. J. Blenis, H. Walczak, J. Tschopp, and C. Belka for providing valuable materials. This work was supported by grants from the German Federal Ministry of Education, Science, Research and Technology; the Interdisciplinary Center of Clinical Research Center of the University of Münster and the Deutsche Forschungsgemeinschaft (LO 823/1-1).

\section{REFERENCES}

1. Gao, D., and Critser, J.K. (2000) Mechanisms of cryoinjury in living cells. ILAR J. 41, 187-196

2. Mazur, P. (1984) Freezing of living cells: mechanisms and implications. Am. J. Physiol. 247, C125-142

3. Bilzer, M., and Gerbes, A.L. (2000) Preservation injury of the liver: mechanisms and novel therapeutic strategies. J. Hepatol. 32, 508-515

4. Hansen, T.N., Dawson, P.E., and Brockbank, K.G. (1994) Effects of hypothermia upon endothelial cells: mechanisms and clinical importance. Cryobiology 31, 101-106

5. Jaeschke, H. (1996) Preservation injury: mechanisms, prevention and consequences. J. Hepatol. 25, 774-780

6. Kruuv, J., Glofcheski, D., Cheng, K.H., Campbell, S.D., Al Qysi, H.M., Nolan, W.T., and Lepock, J. R. (1983) Factors influencing survival and growth of mammalian cells exposed to hypothermia. I. Effects of temperature and membrane lipid perturbers. J. Cell Physiol. 115, 179185

7. Peters, S.M., Rauen, U., Tijsen, M.J., Bindels, R.J., van Os, C.H., de Groot, H., and Wetzels, J.F. (1998) Cold preservation of isolated rabbit proximal tubules induces radical-mediated cell injury. Transplantation 65, 625-632

8. Rauen, U., Polzar, B., Stephan, H., Mannherz, H.G., and de Groot, H. (1999) Cold-induced apoptosis in cultured hepatocytes and liver endothelial cells: mediation by reactive oxygen species. FASEB J. 13, 155-168

9. Eroglu, A., Russo, M.J., Bieganski, R., Fowler, A., Cheley, S., Bayley, H., and Toner, M. (2000) Intracellular trehalose improves the survival of cryopreserved mammalian cells. Nat. Biotechnol. 18, 163-167

10. Coundouris, J.A., Grant, M.H., Engeset, J., Petrie, J.C., and Hawksworth, G.M. (1993) Cryopreservation of human adult hepatocytes for use in drug metabolism and toxicity studies. Xenobiotica 23, 1399-1409 
11. Hollister, W.R., Mathew, A.J., Baust, J.G., and Van Buskirk, R.G. (1998) The effects of freezing on cell viability and mechanisms of cell death in an in vitro human prostate cancer cell line. Mol. Urol. 2, 13-18

12. Budihardjo, I., Oliver, H., Lutter, M., Luo, X., and Wang, X. (1999) Biochemical pathways of caspase activation during apoptosis. Annu. Rev. Cell Dev. Biol. 15, 269-290

13. Los, M., van de Craen, M., Penning, C.L., Schenk, H., Westendorp, M., Baeuerle, P.A., Dröge, W., Krammer, P.H., Fiers, W., and Schulze-Osthoff, K. (1995) Requirement of an ICE/Ced-3 protease for Fas/Apo-1-1mediated apoptosis. Nature 371, 81-83

14. Los, M., Wesselborg, S., and Schulze Osthoff, K. (1999) The role of caspases in development, immunity, and apoptotic signal transduction: lessons from knockout mice. Immunity 10, 629-639

15. Yuan, J., Shaham, S., Ledoux, S., Ellis, H.M., and Horvitz, H.R. (1993) The C. elegans cell death gene ced-3 encodes a protein similar to mammalian interleukin-1 $\beta$-converting enzyme. Cell 75, 641-652

16. Juo, P., Woo, M. S., Kuo, C. J., Signorelli, P., Biemann, H. P., Hannun, Y. A., and Blenis, J. (1999) FADD is required for multiple signaling events downstream of the receptor Fas. Cell Growth Differ. 10, 797-804

17. Kataoka, T., Schroter, M., Hahne, M., Schneider, P., Irmler, M., Thome, M., Froelich, C. J., and Tschopp, J. (1998) FLIP prevents apoptosis induced by death receptors but not by perforin/granzyme B, chemotherapeutic drugs, and gamma irradiation. J. Immunol. 161, 39363942

18. Belka, C., Rudner, J., Wesselborg, S., Stepczynska, A., Marini, P., Lepple-Wienhues, A., Faltin, H., Bamberg, M., Budach, W., and Schulze-Osthoff, K. (2000) Differential role of caspase-8 and BID activation during radiation- and CD95-induced apoptosis. Oncogene 19, 1181-1190

19. Engels, I.H., Stepczynska, A., Stroh, C., Lauber, K., Berg, C., Schwenzer, R., Wajant, H., Janicke, R.U., Porter, A.G., Belka, C., Gregor, M., Schulze-Osthoff, K., and Wesselborg, S. (2000) Caspase-8/FLICE functions as an executioner caspase in anticancer drug-induced apoptosis. Oncogene 19, 4563-4573

20. Rudner, J., Lepple-Wienhues, A., Budach, W., Berschauer, J., Friedrich, B., Wesselborg, S., Schulze-Osthoff, K., and Belka, C. (2001) Wild-type, mitochondrial and ER-restricted Bcl-2 inhibit DNA damage-induced apoptosis but do not affect death receptor-induced apoptosis. $J$. Cell Sci. 114, 4161-4172

21. Cassens, U., Momkvist, P.H., Zuehlsdorf, M., Mohr, M., Kienast, J., Berdel, W.E., and Sibrowski, W. (2001) Kinetics of standardized large volume leukapheresis (LVL) in patients do not show a recruitment phenomenon of peripheral blood progenitor cells (PBPC). Bone Marrow Transplant. 28, 13-20 
22. Eaves, C.J., and Eaves, A.C. (1978) Erythropoietin (Ep) dose response curves for three classes of erythroid progenitors in normal human marrow and in patients with polycythemia vera. Blood 52, 1196-1210

23. Renz, A., Berdel, W. E., Kreuter, M., Belka, C., Schulze-Osthoff, K., and Los, M. (2001) Rapid extracellular release of cytochrome $\mathrm{c}$ is specific for apoptosis and marks cell death in vivo. Blood 98, 1542-1548.

24. Los, M., Khazaie, K., Schulze Osthoff, K., Baeuerle, P. A., Schirrmacher, V., and Chlichlia, K. (1998) Human T cell leukemia virus-I (HTLV-I) Tax-mediated apoptosis in activated T cells requires an enhanced intracellular prooxidant state. J. Immunol. 161, 3050-3055

25. Los, M., Mozoluk, M., Ferrari, D., Stepczynska, A., Stroh, C., Renz, A., Herceg, Z., Wang, Z.Q., and Schulze-Osthoff, K. (2002) Activation and caspase-mediated inhibition of PARP: a molecular switch between fibroblast necrosis and apoptosis in death receptor signaling. Mol. Biol. Cell 13, 978-988

26. Eilers, M., Picard, D., Yamamoto, K.R., and Bishop, J.M. (1989) Chimaeras of myc oncoprotein and steroid receptors cause hormone-dependent transformation of cells. Nature 340, 66-68

27. Burek, C., Roth, J., Koch, H. G., Harzer, K., Los, M., and Schulze-Osthoff, K. (2001) The role of ceramide in receptor- and stress-induced apoptosis studied in acidic ceramidase-deficient Farber disease cells. Oncogene 20, 6493-6502

28. Evan, G.I., Wyllie, A.H., Gilbert, C.S., Littlewood, T.D., Land, H., Brooks, M., Waters, C.M., Penn, L.Z., and Hancock, D.C. (1992) Induction of apoptosis in fibroblasts by c-myc protein. Cell 69, 119-128.

29. Prendergast, G.C. (1999) Mechanisms of apoptosis by c-Myc. Oncogene 18, 2967-2987

30. Fowke, K.R., Behnke, J., Hanson, C., Shea, K., and Cosentino, L.M. (2000) Apoptosis: a method for evaluating the cryopreservation of whole blood and peripheral blood mononuclear cells. $J$. Immunol. Methods 244, 139-144

31. Sadowski-Debbing, K., Coy, J.F., Mier, W., Hug, H., and Los, M. (2002) Caspases-their role in apoptosis and other physiological processes as revealed by knock-out studies. Arch. Immunol. Ther. Exp. 50, 19-34

32. Schulze-Osthoff, K., Ferrari, D., Los, M., Wesselborg, S., and Peter, M.E. (1998) Apoptosis signaling by death receptors. Eur. J. Biochem. 254, 439-459

33. Borner, C., and Monney, L. (1999) Apoptosis without caspases: an inefficient molecular guillotine? Cell Death Differ. 6, 497-507

34. Hubel, A. (2001) Cryopreservation of HPCs for clinical use. Transfusion 41, 579-580. 
35. Rowley, S. D. (1992) Hematopoietic stem cell cryopreservation: a review of current techniques. J. Hematother. 1, 233-250

36. Kato, S., Yabe, H., Yasui, M., Kawa, K., Yoshida, T., Watanabe, A., Osugi, Y., Horibe, K., and Kodera, Y. (2000) Allogeneic hematopoietic transplantation of CD34+ selected cells from an HLA haplo-identical related donor. A long-term follow-up of 135 patients and a comparison of stem cell source between the bone marrow and the peripheral blood. Bone Marrow Transplant. 26, 1281-1290

37. Longthorne, V.L., and Williams, G.T. (1997) Caspase activity is required for commitment to Fas-mediated apoptosis. EMBO J. 16, 3805-3812

38. Los, M., Stroh, C., Janicke, R.U., Engels, I.H., and Schulze Osthoff, K. (2001) Caspases: more than just killers? Trends. Immunol. 22, 31-34

39. Zeuner, A., Eramo, A., Peschle, C., and De Maria, R. (1999) Caspase activation without death. Cell Death Differ. 6, 1075-1080

40. De Maria, R., Zeuner, A., Eramo, A., Domenichelli, C., Bonci, D., Grignani, F., Srinivasula, S.M., Alnemri, E.S., Testa, U., and Peschle, C. (1999) Negative regulation of erythropoiesis by caspase-mediated cleavage of GATA-1. Nature 401, 489-493

41. Zermati, Y., Garrido, C., Amsellem, S., Fishelson, S., Bouscary, D., Valensi, F., Varet, B., Solary, E., and Hermine, O. (2001) Caspase activation is required for terminal erythroid differentiation. J. Exp. Med. 193, 247-254

42. Fu, T., Guo, D., Huang, X., O'Gorman, M.R., Huang, L., Crawford, S.E., and Soriano, H. E. (2001) Apoptosis occurs in isolated and banked primary mouse hepatocytes. Cell Transplant. 10, 59-66 
Fig. 1
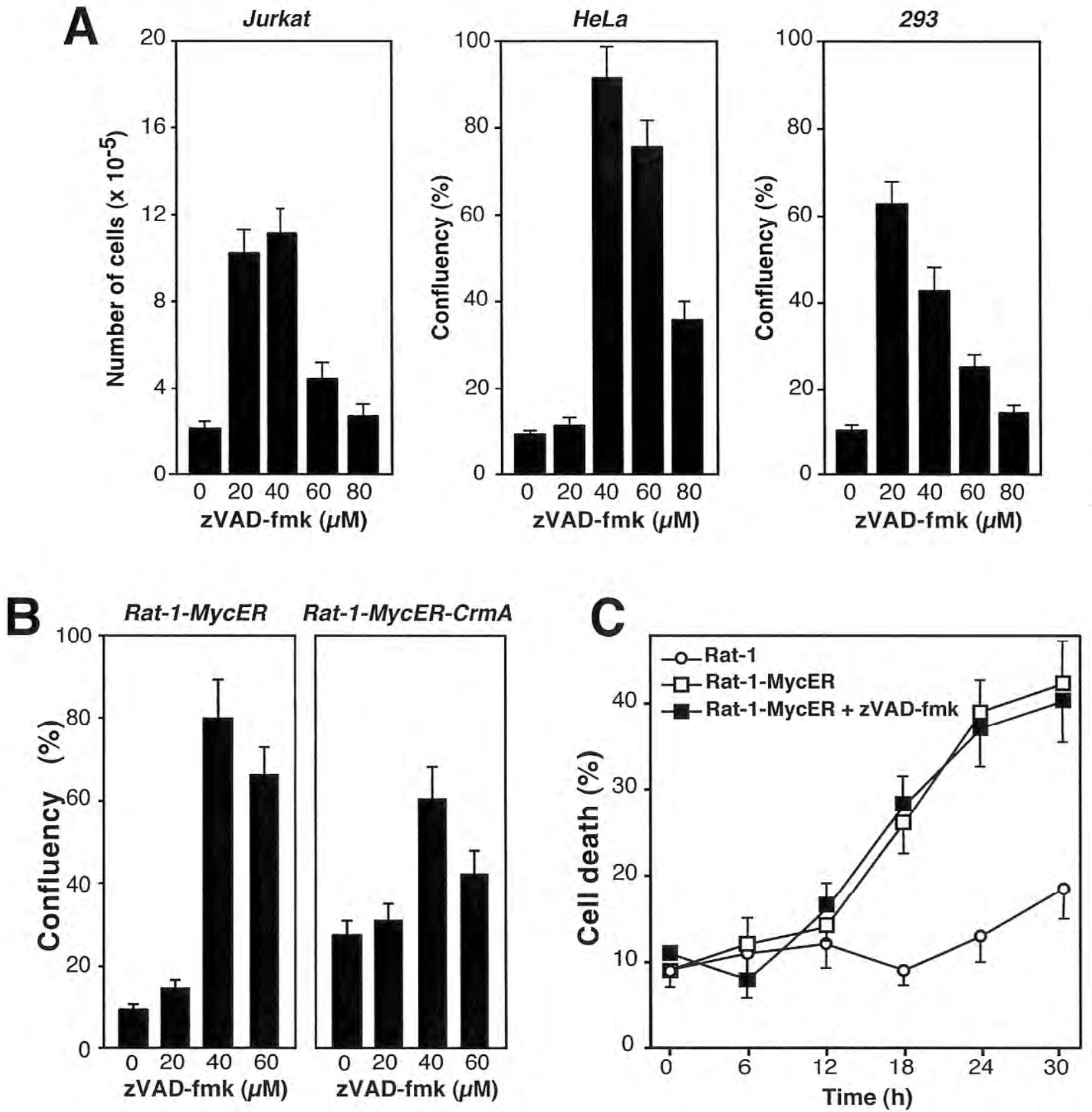

Figure 1. Inhibition of caspases enhances survival and recovery of various cryopreserved cell lines.

A) Effect of the caspase inhibitor zVAD-fmk in different cell types. Jurkat, HeLa, and 293 cells were transferred from liquid nitrogen, thawed, and cultured in the presence and absence of the indicated concentrations of zVAD-fmk. Twentyfour hours after thawing, zVAD-fmk was removed. Following 4 days of culture, the number of cells or the confluency of the wells was determined. B) Effect of CrmA overexpression or zVAD-fmk in Rat-1-MycER fibroblasts. Rat-1-MycER cells, transfected with an expression construct of the caspase inhibitor CrmA or a vector control, were thawed in the presence and absence of the zVAD-fmk as described above. Cell recovery was assessed by measuring cell confluency after 4 days of culture. The data in $\mathbf{A}$ and $\mathbf{B}$ show the mean \pm SD of three independent experiments evaluated by two scientists. C) Myc-induced apoptosis is not affected by pretreatment of cryopreserved cells with zVAD-fmk. Cells were thawed and cultured for $24 \mathrm{~h}$ in the presence or absence of $30 \mu \mathrm{M} \mathrm{zVAD}$-fmk. After $1 \mathrm{wk}$, apoptosis was induced in serum-starved cultures by estrogen-induced c-Myc activation. Apoptosis was determined by propidium iodide uptake $24 \mathrm{~h}$ after estrogen addition. Mean data \pm SD from triplicate samples of a representative experiment are shown. 
Fig. 2
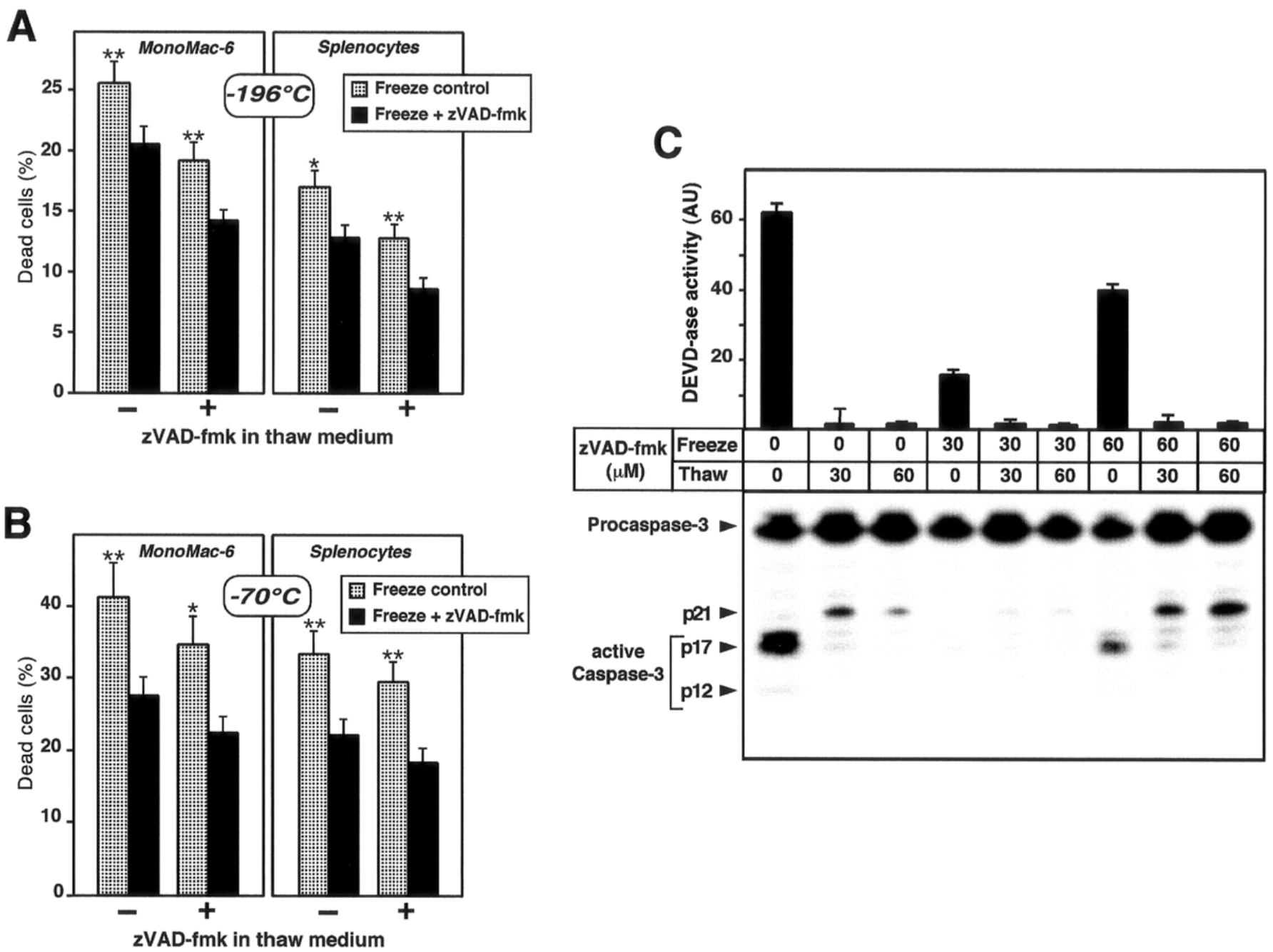

Figure 2. Differential effect of zVAD-fmk on cell survival and caspase activation during the freeze and thaw process. A, B) The monocytic cell line MonoMac-6 and murine splenocytes were frozen in standard freeze medium in the presence or absence of $30 \mu \mathrm{M} \mathrm{zVAD}$-fmk. Cells were then either stored in liquid nitrogen (A) or at $-70^{\circ} \mathrm{C}(\mathbf{B})$. Fourteen months after they were frozen, cells were thawed in culture medium in the presence or absence of $30 \mu \mathrm{M} z \mathrm{VAD}$ fmk. Two hours after the cells were thawed, cell death was assessed by the uptake of Trypan blue. Results are given as mean \pm SD from two thawed vials measured in tetraplicate cultures. For statistical analysis, we applied the Student's $t$ test. Statistical significance was considered, if $P<0.01(* P<0.01, * * P<0.005)$. C) Activation of caspase-3 in cultures of cells frozen and thawed in the presence and absence of zVAD-fmk. Jurkat cells were frozen with or without the indicated concentrations of zVAD-fmk. After 3 wk of storage in liquid nitrogen, cells were thawed in the presence or absence of the caspase inhibitor. Six hours later, cells were lysed and subjected to the DEVDase assay (upper panel) or immunoblotting (lower panel), using a caspase-3-specific antibody. The immunoblot shows the 32-kDa precursor of caspase-3, the inactive p21 intermediate fragment, and the p17 and p12 active subunits. The experiments were performed twice in Jurkat cells and also in 293 and caspase-3-expressing MCF-7 cells with essentially the same results. 
Fig. 3
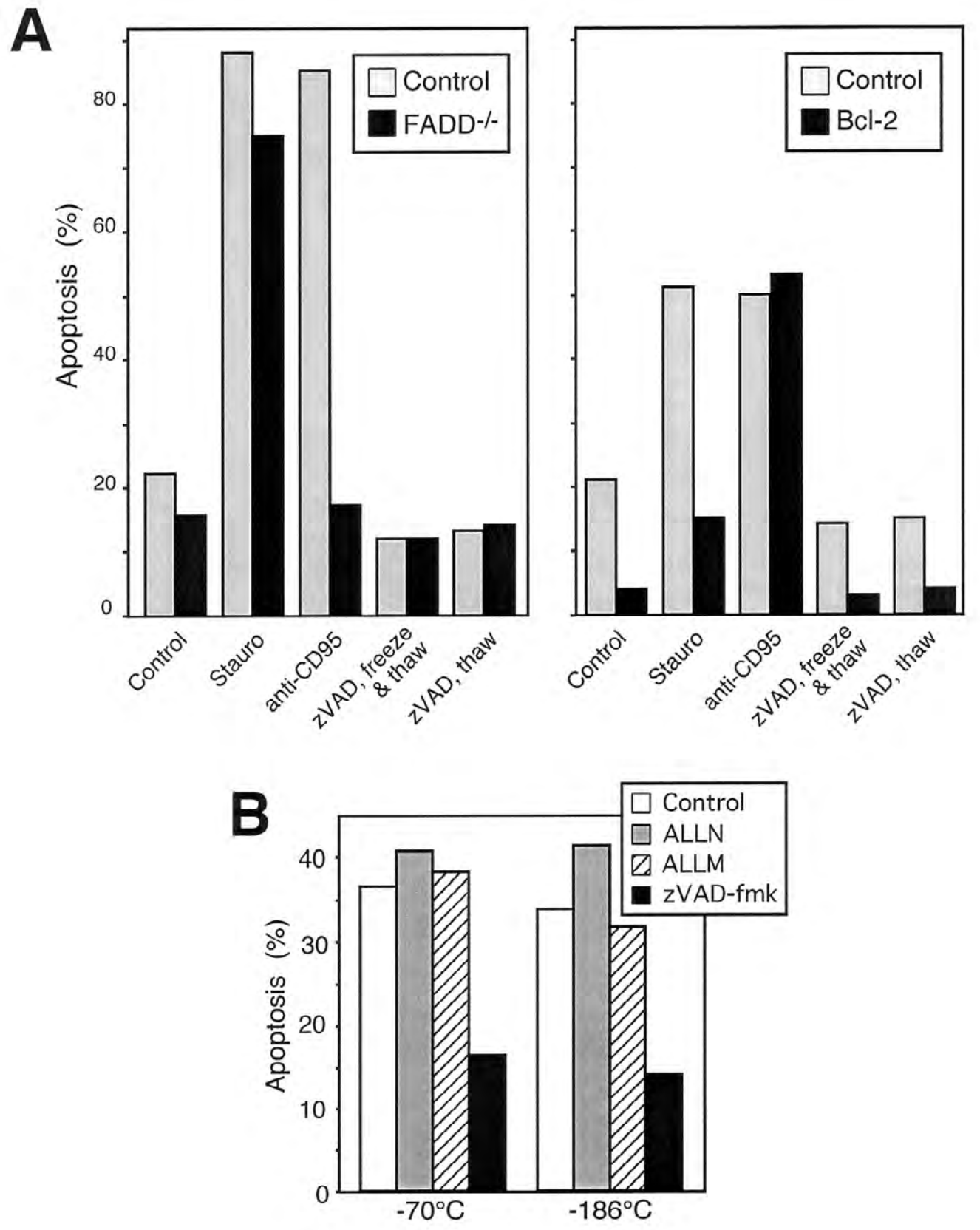

Figure 3. Cryoinjury-induced apoptosis is Bcl-2-controlled but death receptor-independent and does not require calpain or cathepsin proteases. A) FADD-deficient and parental Jurkat cells (left panel) or Jurkat cells overexpressing $\mathrm{Bc}-2$ and the respective vector control (right panel) were frozen at $-70^{\circ} \mathrm{C}$ in the presence or in the absence of $30 \mu \mathrm{M}$ zVAD-fmk (zVAD) for 7 days. All cell lines were $>98 \%$ viable before freezing as assessed by Trypan blue exclusion. Cells were thawed in the presence or in the absence of zVAD-fmk and incubated in growth medium at $37^{\circ} \mathrm{C}$ for $6 \mathrm{~h}$. Cells were harvested, and apoptosis was assessed by the formation of hypodiploid DNA and flow cytometry. As a control, cells were also treated with anti-CD95 $(1 \mu \mathrm{g} / \mathrm{ml})$ or staurosporine (Stauro) $(2.5 \mu \mathrm{M}) 1 \mathrm{~h}$ after thawing and incubated for an additional $5 \mathrm{~h}$. B) Effect of calpain and cathepsin inhibitors on cryoinjury-induced apoptosis. Jurkat cells were frozen either at $-70^{\circ} \mathrm{C}$ or at $-186^{\circ} \mathrm{C}$. After 7 days, cells were thawed in culture medium supplemented with the calpain inhibitor $\operatorname{ALLN}(2.5 \mu \mathrm{M})$, the calpain/cathepsin inhibitor ALLM $(2.5 \mu \mathrm{M})$, or the caspase inhibitor zVAD-fmk $(30 \mu \mathrm{M})$. The percentage of apoptosis was determined after $6 \mathrm{~h}$ by measuring the formation of hypodiploid DNA. Higher concentrations of ALLN or ALLM were toxic. Furthermore, the cathepsin B-specific inhibitor CA-074-ME was unable to prevent cryoinjury-induced apoptosis at various concentrations (data not shown). The results in $\mathbf{A}$ and $\mathbf{B}$ indicate the mean of triplicate samples of a representative experiment out of three. The standard deviation was $<9 \%$. 
Fig. 4
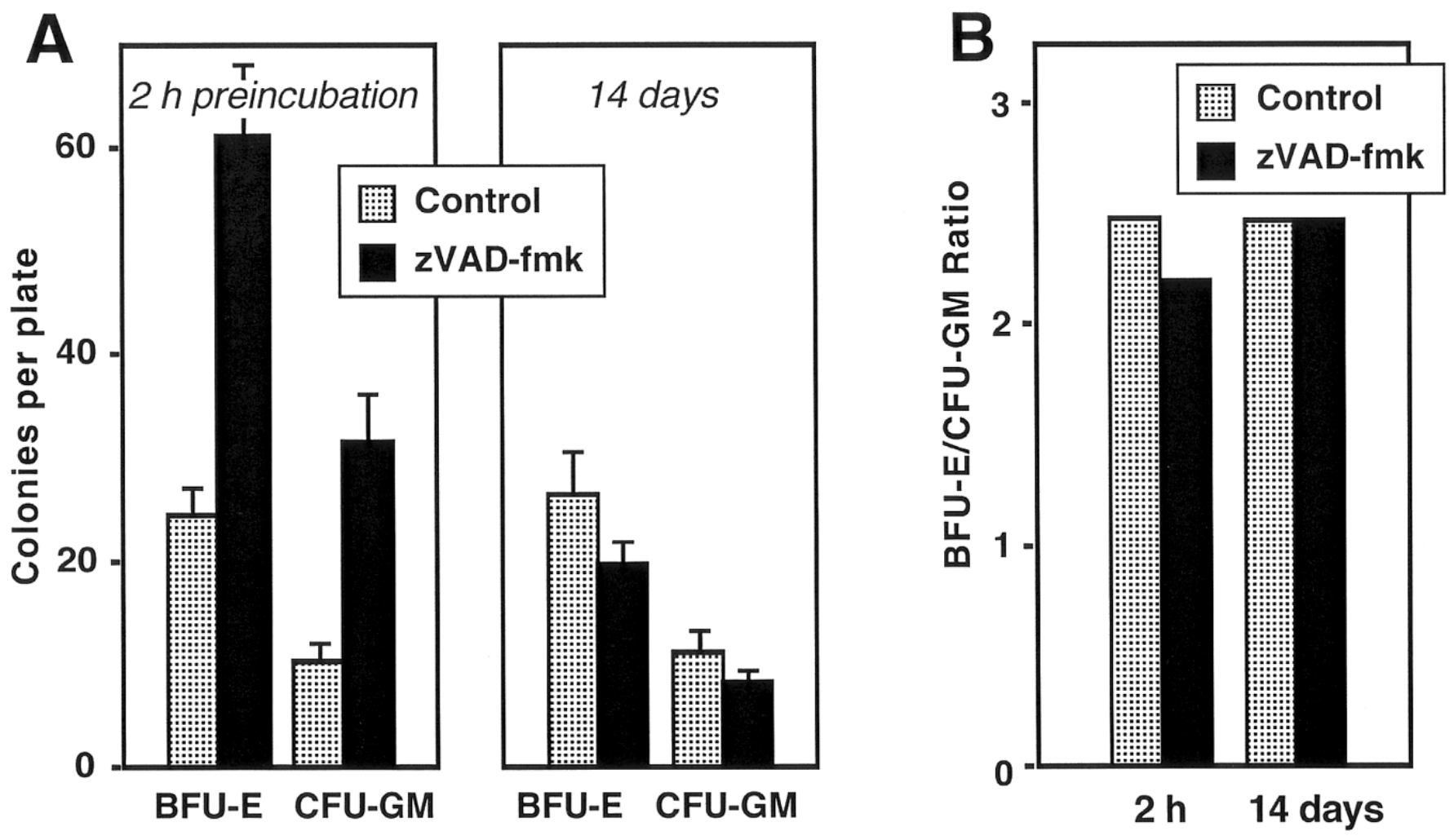

Figure 4. Inhibition of caspase activity strongly improves clonogenicity of cryopreserved hematopoietic stem cells. A) hematopoietic progenitor cells (HPC) were frozen in liquid nitrogen and thawed in culture medium in the presence and absence of $30 \mu \mathrm{M}$ zVAD-fmk. The left panel shows experiments with cells preincubated for $2 \mathrm{~h}$ with or without the caspase inhibitor, before the cells were further incubated on methylcellulose in the absence of zVAD-fmk. The right panel shows results with cells that were continuously incubated in methylcellulose medium containing $30 \mu \mathrm{M}$ zVAD-fmk for 14 days. Two weeks after the thaw process, the number of erythroid progenitor-derived colonies (BFU-E) and granulocytemacrophage progenitor-derived colonies (GM-CFU) was determined. The data show results with HPC cultures from one representative donor measured in duplicate cultures. B) Calculation of the BFU-E/GM-CFU ratio revealed that incubation with $\mathrm{zVAD}$-fmk for $2 \mathrm{~h}$ or 14 days did not strongly affect the cellular composition of HPC cultures. 